\title{
PRINCIPLES OF THE APPLICATION OF STRATEGIC PLANNING METHODS
}

\author{
Marek Lisiński ${ }^{1}$, Mark Šaruckij ${ }^{2}$ \\ Cracow University of Economics, Rakowicka 27, 31-510 Krakow, Poland \\ E-mail: 'lisinski@ae.krakow.pl; ${ }^{2}$ saruckim@ae.krakow.pl \\ Received 0311 2005; accepted 06022006
}

\begin{abstract}
Strategic planning methods form an extensively developed and interrelated group of dozens of methods used for organisation strategy development. Research has confirmed that only a small amount of firms use strategic planning methods in practice due to different reasons. The publications on strategic planning are devoted mostly to theoretical issues or empirical characteristics of chosen sub-problems related to this concept of management. The methodological aspects, if at all, are taken into account as marginal or of minor importance. The purpose of this article is to present the principles of strategic planning methods classification and application. The methodology used in this research is based on the taxonomy methods and particularly Ward's method. A total amount of 28 different strategic planning methods were chosen and classified in our study.
\end{abstract}

Keywords: strategic management, strategic planning methods, classification.

\section{Introduction}

The concept of strategic management can be defined as the art and science of formulating, implementing, and evaluating cross-functional decisions that enable an organisation to achieve its objectives $[1$, p. 5]. Over the years there a steady growth of interest has been observed among both practitioners and theoreticians of management in strategic planning methods [2-5]. Based on the extensive literature review [1, 6-11], strategic planning is defined as the process of determining an organisation's long-term goals and then identifying the best approach for achieving those goals. Strategic planning originated in the 1950s and was very popular between the mid-1960s to mid1970s. During these years, strategic planning was widely believed to be the answer for all problems met by business organisations. Nevertheless, strategic planning was cast aside during the 1980s as various planning methods did not yield higher returns. However, the 1990s brought the revival of strategic planning, and the process is widely practiced nowadays in the business world $[1, \mathrm{p} .5]$. The term strategic management in this paper is used synonymously with the term strategic planning.
Strategic planning methods form an extensively developed and interrelated group of dozens of methods used for organisation strategy development. The significance of using methods to increase a given company's competitive advantage is growing, because of the changing needs to create and use the organisation's strategy development. Intuitive or routine ways of problem solving with methods used up until now turned out to be fallible or ineffective $[12$, p. 7]. Research has confirmed that only a small amount of firms use strategic planning methods in practice due to different reasons [1, p. 16].

The publications on strategic planning are devoted mostly to theoretical issues or empirical characteristics of chosen sub-problems related to this concept of management $[7,8]$. The methodological aspects, if at all, are taken into account as marginal or of minor importance. After extensive research into the literature, a lack of a comprehensive study devoted to strategic planning methods categorisation was noticed. Thus, the purpose of this article is to present principles of strategic planning methods categorisation and a classification of strategic planning methods. 


\section{Foundations for strategic planning methods classification}

Numerous studies in strategic management attempted to sort out methods used for strategic management [1$4,7-9,11,13-19]$. Nevertheless, only few of them could be treated to some extent as classification, since not all the attributes of the term classification are met. Various definitions of "classification" can be found in the literature of the subject [20-22]. For the purpose of our study the most relevant understanding of that term is considering it a process of splitting-combining, which throughout a multifunctional structure transformation of a studied collection of components or object, puts in order their elements [23]. Such an order, defined as systematisation leading to distinguishing the groups of similar elements, is the result of that process.

The group of the following 28 methods of strategic planning were chosen as the subject for classification: PEST Analysis [11, p. 104], Porter's Diamond [24], Stakeholder Mapping [25], Economic Prognosis Methods [26], Strategic Gap Analysis [26], QUEST Analysis [27], Scenario-based Analysis [26], Comb Analysis [28], Experience Curve [29, p. 79], External Factor Evaluation (EFE) Matrix [1, p. 113], Competitive Profile Matrix (CPM) [1, p. 115], Porter's Five Forces Model [29, p. 31], Industry Value Analysis [29, p. 46], Strategic Group Analysis [11, p. 127], Industry Life Cycle Analysis [26, p. 191], Internal Factor Evaluation (IFE) Matrix [1, p. 153], Firm's Strategic Balance Analysis [26, p. 163], Multiple Firm's Activity Qualification Analysis [30, p. 193], Key Factors for Success Analysis [31, p. 82], Value Chain Analysis [32], Life Cycle/Portfolio Matrix [1, p. 217], Portfolio Matrix Analysis [11, p. 186], SWOT Analysis [31, p. 87], Strategic Reflection Method [33], Strategic Development Matrix [34], ASTRA Method [30, p. 198-217], HOSHIN Method [35] and SPACE Analysis [36]. Each method was analysed as a socalled operative taxonomical unit.

There were two main purposes of the classification process, being:

1) To sort the types of strategic planning methods, assuming three classification areas: the scope of method utility, the way of conducting analysis, and the conditions of using a method;

2) To point out the principles of using the methods.

The classification framework was defined by a set of features characterizing the given collection of methods, and were used as evaluation criteria. Finally, eleven main and 34 sub-criteria for strategic planning methods assessment were formulated (See Table 1). All distinguished criteria were considered of equal weight. For each of them a variable number of subcriteria was determined, and values from 1 to $n$ were given, where $n$ is the number of a sub-criteria.

Selecting an appropriate taxonomical technique from a plenty of available ones, was the next essential step for classifying strategic planning methods. From the point of the aim of our study the most appropriate techniques belong to the agglomerative techniques group. Among several techniques belonging to that group $^{1}$ the most effective, which is Ward's method [22, p. 12], was selected. This method, originating from the group of hierarchical agglomerative techniques, enables to determine a tree-hierarchy of the analysed group of elements. Using hierarchical taxonomical techniques supported by STATISTICA software, obtaining a comprehensive cluster hierarchy with a monotonically growing similarity ratio is achieved [21, p. 101].

The taxi method was chosen as a measure for length, which is the sum of differences of absolute values corresponding with successive characteristics (evaluation criteria). This length is typical for jumping features that form the analysed classification area [12, p. 304]. It was assumed that each evaluation criteria from $A$ to $K$ are of the same importance in the classification process.

The final classification in the form of a dendrogram, was prepared using an analysis of tree links shape and growth in agglomerative lengths. To verify the results of the defined groups the frequency of occurrence of sub-criteria in relation to methods included in each group were analysed. To achieve that aim the contingency tables were prepared consisting of a chisquare test of independence enabling statistical verification of the significance of group differentiation by "answers" framed by specific criteria. A given subcriteria has a substantial differentiation for the groups, if the value $p$ from the chi-square test is less than the assumed significance level $\alpha=0.05$.

\section{Categorisation of strategic planning methods}

The general categorisation of strategic planning methods brings valuable insights into better understanding of these methods. During the

A taxonomical group of methods enables to classify by qualitative characteristics and consists of such techniques as Smirnov's method, descriptive technique, dendritic tree or Ward's method. See [9 p. 15]. 


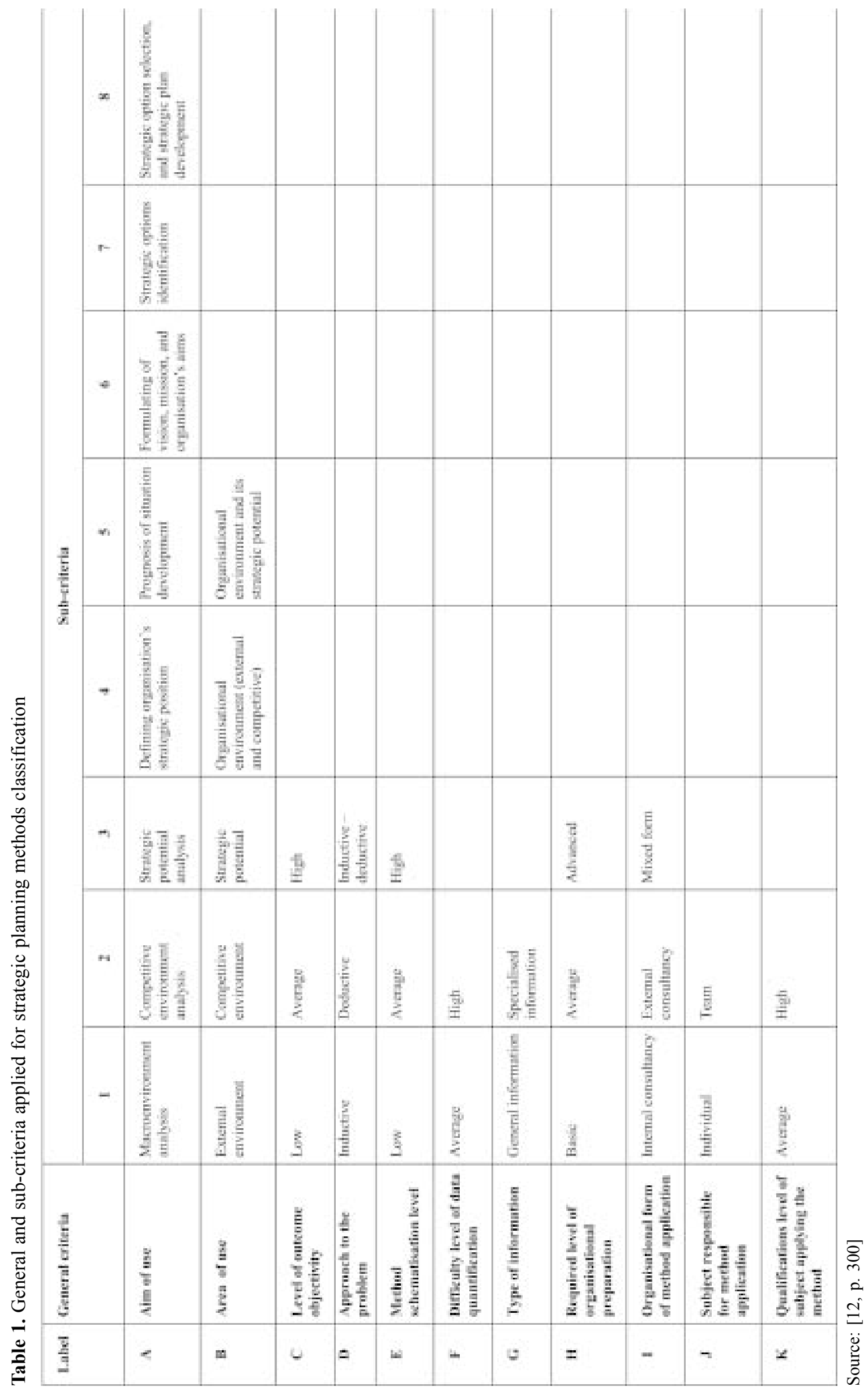


classification of strategic planning methods process, three classification areas, as it was mentioned earlier, were assumed. Each of them includes: the scope of method utility (consisting of three general criteria: Aim of use a method $A$, Area of use a method $B$, and Level of outcome objectivity $C$ ), the way of conducting analysis (consisting of four general criteria: Approach to the problem $D$, Method schematisation level $E$, Difficulty level of data quantification $F$, and Type of information $G$ ), and the conditions of using a method (consisting of four general criteria: Required level of organisational preparation $H$, Organisational form of method application $I$, Subject responsible for method application $J$, and Qualification level of subject applying the method $K$ ). A classification of methods for each of the three described areas was prepared. (See 12, p. 305-314). After applying all subcriteria with the help of the agglomerative procedure a dendrogram was created (see Fig 1).

The results from the dendrogram indicate that, taking into account all criteria, the analysed strategic planning methods were classified into four groups, see Table 2.

The first group includes the following four methods: P1 PEST Analysis, P8 Comb Analysis, P9 Experience Curve, and P15 Industry Life Cycle Analysis. The second one consists of five methods: P5 Strategic Gap Analysis, P10 External Factor Evaluation (EFE)

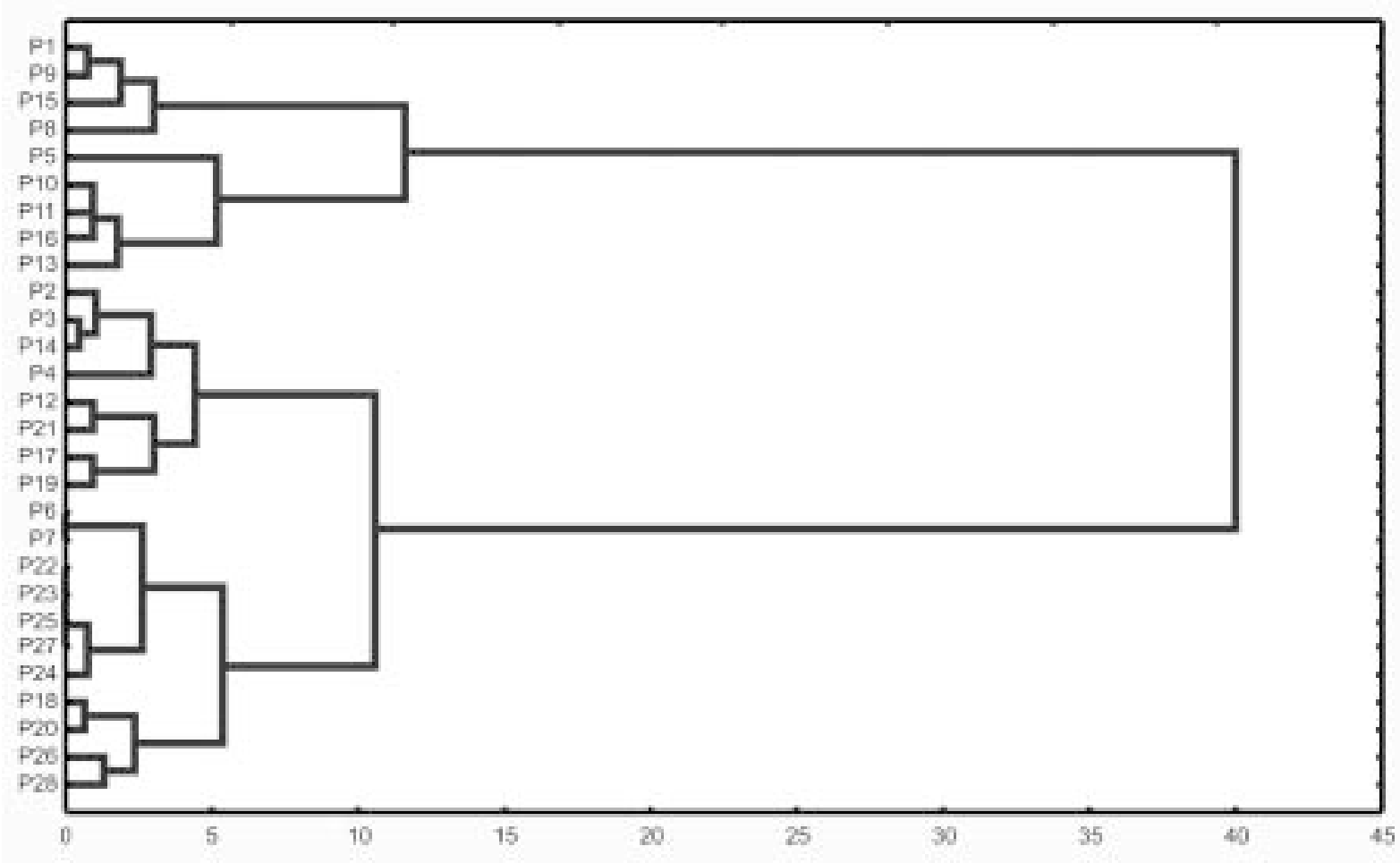

Fig 1. A dendrogram tree based on Ward's method, all criteria applied Source: [12, p. 315]

Table 2. Classification of strategic planning methods

\begin{tabular}{|c|c|c|c|}
\hline \multicolumn{4}{|c|}{ Methods } \\
\hline \multicolumn{2}{|c|}{ Companies with general level of organisational preparation } & \multicolumn{2}{|c|}{ Companies with average level of organisational preparation } \\
\hline 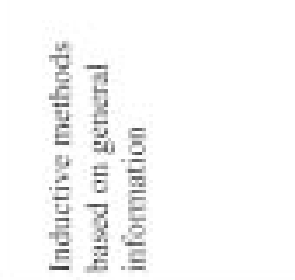 & 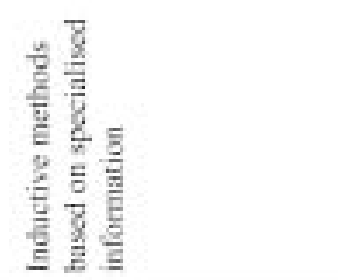 & 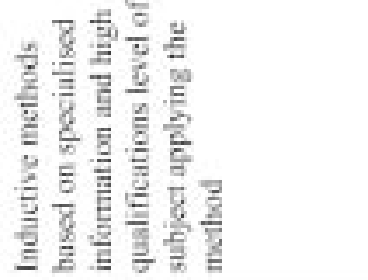 & 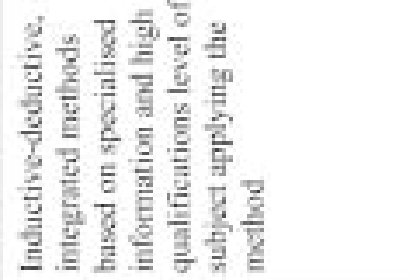 \\
\hline Pl. P8, PQ, PI5 & P5. P10, P1/, P/3. P/6 & $\begin{array}{c}\text { P2. P3. P4, Pl2,Pl4, Pl7. } \\
\text { Pl9, P2I }\end{array}$ & $\begin{array}{c}P 6_{1}, P 7, P 18, P 20, P 22, P 23 \\
P 24, P 25, P 26, P 27, P 28\end{array}$ \\
\hline
\end{tabular}

Source: [adapted from 12, p. 315 
Matrix, P11 Competitive Profile Matrix (CPM), P13 Industry Value Analysis, and P16 Internal Factor Evaluation (IFE) Matrix. Eight methods belong to the third group, they are: P2 Porter's Diamond, P3 Stakeholder Mapping, P4 Economic Prognosis Methods, P12 Porter's Five Forces Model, P14 Strategic Group Analysis, P17 Firm's Strategic Balance Analysis, P19 Key Factors for Success Analysis, and P21 Life Cycle/Portfolio Matrix. The last group consists of eleven methods: P6 QUEST Analysis, P7 Scenario-based analysis, P18 Multiple Firm's Activity Qualification Analysis, P20 Value Chain Analysis, P22 Portfolio Matrix Analysis, P23 SWOT Analysis, P24 Strategic Reflection Method, P25 Strategic Development Matrix, P26 ASTRA Method, P27 HOSHIN Method, and P28 SPACE Analysis.

Among all four groups of strategic planning methods the first one is the most homogenous. This group of methods can be used by an organisation possessing general technical-organisational conditions. To apply the methods of this group it is not required to have either high methodological prerequisites (since these methods are inductive) or particular conditions related to qualifications level of the subject's applying the method. This leads to decisions that are not characterised by a high level of objectivity. It is important to mention one of their main attributes. These research instruments can be used for an analysis of all three areas - the macroenvironment, the competitive environment, and the organisation's strategic potential throughout the time of organisation strategy formulation.

The second group of methods is more diversified in its structure, and includes such investigation instruments, which from the point of view of several criteria are similar to the methods from the first group. This similarity is characterised by a required level of organisational preparation, methodological form of analysis or qualifications level of a subject applying the method. Differences can be seen first of all in the use of specialised information followed by data quantification difficulty.

The third group consists of methods related to an organisation, which is characterised by at least an average level of preparation, taking into account technical-organisational conditions or structural decisions. These methods are inductive, nevertheless a high qualifications level of a subject applying the method and the help of internal or external consultants is required. On one hand, application of these methods requires using specialised information, which is extremely difficult to quantify. On the other hand, the methods of that group can be used for analysis of external and internal environment as well as the organisation's strategic potential, and therefore, are helpful in developing organisation's strategy.

The last group consists of methods, that, in order to develop a strategy, have at least an average level of organisational preparation. A subject applying a method should have high qualifications. In most cases an external or internal consultancy is needed. These methods are based on an inductive-deductive approach to the problem, use specialised information that leads to a high level of difficulty of data quantification, and in most cases (except QUEST analysis, Scenario-based methods, Multiple Firm's Activity Qualification Analysis, and Value Chain Analysis) are the so-called integrated methods.

\section{Practical directions for using strategic planning methods}

The main conclusion arising from the method classification presented above refers to the importance of the conditions of method using for the appropriate method application. This aspect of evaluation concerns all the methods and is the main requirement for their effective application.

The technical-organisational conditions are of the greatest importance and should be seen in terms of a highly extended technical and organisational infrastructure enabling the processing of information for strategy development. This main aspect is complemented by other additional elements. The organisational form of a method application presents a kind of the organisation's readiness for problems, associated with strategy formulation and solving. The subject using the method is an important practical aspect, from the point of view of effective method application. It can be argued from the analysis of the dendrogram of strategic planning methods that almost all the methods are based on the interdisciplinary research team. The last significant aspect is an appropriate and essential methodical preparation of the persons applying the method. The level of qualifications and competence is especially important and determines the possibility of using of some methods.

It is important to mention that together with conditions of methods application, the CEO's influence is an important factor in deciding which methods of strategy development can be used.

When an organisation is characterised by a general level of preparation for strategy development, in order 
to obtain better effects it is possible to use inductive methods based on the use of general information. In that group of methods could be found such methods as: PEST Analysis, Comb Analysis, Experience Curve or Industry Life Cycle Analysis. These methods are simple, relatively easy to use, although they are considered as imperfect research instruments. It is risky to use this collection of methods for an organisation's strategy development, since it would be hardly possible to argue that the achieved results will be at least of an average level of objectivity. These methods, concentrating on the research of some areas, could be used as a diagnosis or a preface for a more comprehensive analysis. Moreover, it could be indicated their sequence, every single method for analysis of the external environment, internal environment, and organisation's potential, for the purpose of strategy formulation, with the help of main research processes (analysis, diagnosis, modelling and projecting) and the experience of the persons applying the method. On the other hand, it is difficult to conduct such analysis because the fact that the subjects executing particular research tasks possess general qualifications, and therefore can not make a rational decision. Thus, it is not recommended either using methods in such sequence, or formulating conclusions based on the results achieved with the help of these methods.

In the case when an organisation is not characterised by at least an average level of preparation for strategy development, but is determined to conduct an analysis and to receive more trustworthy outcome, it is possible to use one of the following methods: Strategic Gap Analysis, External Factor Evaluation (EFE) Matrix, Competitive Profile Matrix, Industry Value Analysis or Internal Factor Evaluation (IFE) Matrix. All the results of using these methods are based on specialised information, which increases the outcome objectivity. When using these methods the help of external consultants involved in interdisciplinary teams is required more often. Is it possible to create a strategy based on the results of the analysis of that group of methods? It seems possible, although in such cases it is recommended to use a set of several methods for analysis of separate areas of environment and organisation. The broadening of the scope of a research increases the level of result quality, expands the scope of conclusions, and leads to a more comprehensive and complex analysis and evaluation.

The organisation, characterised by at least an average level of organisational preparation for strategy development, has two options of application. The first, and easier one, is to use sequentially methods leading to strategy formulation. This group consists of the following methods: Porter's Diamond, Stakeholder Mapping, Economic Prognosis Methods, Porter's Five Forces Model, Strategic Group Analysis, Firm's Strategic Balance Analysis, Key Factors for Success Analysis, and Life Cycle/Portfolio Matrix. The second one, and the more sophisticated, is based on the applying of integrated methods, using inductivedeductive methodological approach to a problem. The decision about the choice of an appropriate method is made on the basis of the set of following strategic planning methods: QUEST Analysis, Scenario-based analysis, Multiple Firm's Activity Qualification Analysis, Value Chain Analysis, Portfolio Matrix Analysis, SWOT Analysis, Strategic Reflection Method, Strategic Development Matrix, ASTRA Method, HOSHIN Method, and SPACE Analysis. Solving this problem, it is important to remember about some methods which do not perfectly fit in this group that are: QUEST Analysis, Scenario-based analysis, Multiple Firm's Activity Qualification Analysis, and M.E. Porter's Value Chain Analysis. The choice of one or another procedure depends on the function to accomplish during the process of analysis. If it will be a function, which does not fit the requirements of the final aim of the analysis, then an inductive method should be used instead of integrated ones. Both options of the analysis do similarly reflect other sub-criteria, such as analysis with the use of specialised information, high level of requirements for a subject's responsible for applying the method qualifications, or the use of internal or external consultancy as organisational form of the method application.

Last but not least, the important dilemma about the choice of one or several methods of strategic planning is related to the concept of the use of these analytical tools. A choice of an appropriate method does not have to be based on the present organisation's situation, but should be a result of the realisation of a suitable longrange concept of its analysis and development.

\section{Conclusions}

Summing up our considerations, some other practical recommendations should be mentioned. It is important to point out that formulated earlier propositions do not consider all available suggestions specifying the scope of using strategic planning methods. The recommendations should be treated rather as directions of acting than as ready recipe. It would be wrong to use the above suggestions without criticism.

Each conclusion regarding the use of strategic plan- 
ning methods should be analysed separately in the context of a given organisation. The discussion between qualified experts and the organisation's managerial staff leading to consensus should determine the rational direction of acting.

It is significant to bear in mind the fact suggested here that proposes the use of methods, which are flexible and will continue to develop together with a developing organisation and its environment. The observation of those conditions and their evaluation, from the point of view of requirements of strategic planning methods, will increase our practical experience and make easier application of these methods.

Finally, it is expected that the classification of strategic planning methods and recommendations for their practical application presented here will spawn both academic and practical interest in both the use of strategic planning methods and further develop their classification.

\section{References}

[1] David, F. R. Strategic Management, Prentice Hall, Upper Saddle River, 2001.

[2] Hill, Ch.; Jones, G. Strategic Management Theory. An Integrated Approach, Houghton Mifflin, Boston, 1995.

[3] Lynch, R. Corporate Strategy, Prentice Hall, Upper Saddle River, 2000, p. 109.

[4] Mintzberg, H.; Quinn, J. B. The Strategy Process, Concepts, Contexts, Cases, Prentice Hall, Upper Saddle River, 1996.

[5] Quinn, J. B.; Mintzberg, H.; James, R. M. The Strategy Process, Prentice Hall, Upper Saddle River, 1998.

[6] Ansoff, H. I. Corporate Strategy, Penguin Books, Harmonsword, Midlsex, 1969.

[7] Byars, L. L. Strategic Management. Planning and Implementation. Concepts and Cases, Harper and Row, New York, 1987.

[8] Chandler, A. D. Strategy and Structure, The M.I.T. Press, Cambridge, Mass., 1962.

[9] Digman, L. A. Strategic Management, Concepts, Decisions, Cases, Business Publications, Texas, 1986.

[10] Finlay, P. Strategic Management. An Introduction to Business and Corporate Strategy, Pearson Education, Harlow, 2000.

[11] Johnson, G.; Scholes, K. Exploring Corporate Strategy, Text and Cases, Prentice Hall, London 1999.

[12] Lisiński, M. Metody planowania strategicznego, PWE, Warszawa, 2004.

[13] Certo, S.; Peter, J. Strategic Management, Random House, New York, 1988.
[14] Drucker, P. F. Long-Rang Planning, Challenge to Management Science, t.5, Management Science, 1959.

[15] Grant, J. H.; King, W. R. The Logic of Strategic Planning, Little, Brown and Company, Boston-Toronto, 1982.

[16] Hax, A. C.; Majluf, N. S. The Strategy Concept and Process. A Pragmatic Approach, Prentice Hall, Upper Saddle River, 1996.

[17] Pearce, J. A.; Robinson, Jr. R. B. Strategic Management. Formulation, Implementation, and Control, Irwin, Homewood, 1991.

[18] Rue, L. W.; Holland, P. G. Strategic Management, Concepts and Experiences, McGraw-Hill, New York, 1989.

[19] Wheelen, T. L.; Hunger, J. D. Strategic Management, Addison-Wesley, Reading, Mass., 1989.

[20] Gatnar, E. Symboliczne metody klasyfikacji danych, PWN, Warszawa, 1998, p. 13.

[21] Grabiński, T. Metody taksonometrii, Akademia Ekonomiczna, Kraków, 1992.

[22] Grabiński, T.; Wydymus, S.; Zeliaś, A. Metody taksonomii numerycznej $w$ modelowaniu zjawisk społeczno-gospodarczych, PWN, Warszawa, 1989.

[23] Statystyczne metody analizy danych, Ed. W. Ostasiewicz, Akademia Ekonomiczna, Wrocław, 1998.

[24] Porter, M. E. The Competitive Advantage of Nations, The Free Press, New York, 1990, p. 71.

[25] Zarzadzanie strategiczne. Koncepcje, metody, Ed. R. Krupski, Akademia Ekonomiczna, Wrocław, 1999, p. 134.

[26] Gierszewska, G.; Romanowska, M. Analiza strategiczna przedsiźbiorstwa, PWE, Warszawa, 2003.

[27] Naunus, B. QUEST - Quick Environmental Scanning Technique, "Long Range Planning" 1982, No. 2.

[28] Koch, R. Strategia. Jak opracować i wprowadzić w życie najskuteczniejsza strategię. Przewodnik, Wydawnictwo Profesjonalnej Szkoły Biznesu, Kraków, 1998, p. 176.

[29] Strategor, Zarzadzanie firmq. Strategie. Struktury. Decyzje. Tocesamość, PWE, Warszawa, 2001.

[30] Stabryła, A. Zarzadzanie strategiczne $w$ teorii $i$ praktyce firmy, PWN Warszawa-Kraków, 2000.

[31] Thompson, A. A. Strickland A.J., Strategic Management. Concept and Cases, Irwin, New York, 1993.

[32] Porter, M. E. Competitive Advantage, The Free PressMacmillan New York, 1994.

[33] Sierieux, H. Mobiliser l'intelligence de l'entreprise, EME, Paris, 1983.

[34] Nogalski, B.; Rybicki, J. Strategiczne zarzadzanie, TNOiK, Bydgoszcz, 1997, p. 135.

[35] Shiba, S. Le Management par Percee. Methode HOSHIN, INSEP Editions, Paris, 1995, p. 10.

[36] Rowe, A. J.; Mason, R. O.; Dickel, K. E. Strategic Management: A Methodological Approach, AddisonWesley 1986, p. 196-204. 